\title{
Microstructures and Mechanical Properties of Shape Memory Alloy Using Pre-Mixed TiNi Powders with $\mathrm{TiO}_{2}$ Particles $^{* 1}$
}

\author{
Ryoichi Soba $^{1, * 2}$, Yukiko Tanabe ${ }^{1}$, Takayuki Yonezawa ${ }^{2}$, Junko Umeda ${ }^{2}$ and Katsuyoshi Kondoh ${ }^{2}$ \\ ${ }^{1} R \& D$ Center, Terumo Corporation, Ashigarakami-gun, Kanagawa 259-0151, Japan \\ ${ }^{2}$ Joining and Welding Research Institute, Osaka University, Ibaraki 567-0047, Japan
}

\begin{abstract}
In this study, microstructural and mechanical properties of the extruded and heat-treated TiNi alloys by sintering the mixture of TiNi pre-mixed powder with titanium dioxide $\left(\mathrm{TiO}_{2}\right)$ particles were investigated. Pure Ti and pure Ni powder with $\mathrm{TiO}_{2}$ particles were mixed and consolidated by spark plasma sintering (SPS). SPSed TiNi alloy compacts were extruded and heat-treated subsequently. SPSed TiNi alloy compacts had TiNi matrix and $\mathrm{Ti}_{4} \mathrm{Ni}_{2} \mathrm{O}$ phase. $\mathrm{Ti}_{4} \mathrm{Ni}_{2} \mathrm{O}$ phase was formed during SPS by reaction between TiNi matrix and oxygen atoms originated from additive $\mathrm{TiO}_{2}$ particles. Consequently, the heat-treated Ti-50.5 at $\% \mathrm{Ni}$ alloy using pre-mixed powder with 1.0 vol\% TiO 2 particles showed a high plateau stress of $630 \mathrm{MPa}$ and a good shape recovery of $79.7 \%$ in $8 \%$ strain applied. The heat-treated TiNi alloy with 1.0 vol\% $\mathrm{TiO}_{2}$ particles revealed the high strength and good shape memory properties. The high strengthening mechanism of the TiNi alloy using pre-mixed powder with $\mathrm{TiO}_{2}$ particles was mainly due to a decrease martensitic transformation temperature by an increase solute $\mathrm{Ni}$ content in TiNi matrix after reaction between $\mathrm{TiNi}^{\mathrm{N}}$ and $\mathrm{TiO}_{2}$. [doi:10.2320/matertrans. Y-M2017848]
\end{abstract}

(Received September 6, 2017; Accepted October 15, 2017; Published December 25, 2017)

Keywords: TiNi pre-mixed powder, $\mathrm{TiO}_{2}$ particles, shape memory alloy, precipitation, hysteresis

\section{Introduction}

Shape memory alloy (SMA) are practically applied owing to excellent properties, such as shape memory effect with reshape properties when transformed and then heated, superelastic properties with the recovery of the original shape when unloading and damping characteristics with vibrations attenuated ${ }^{1)}$. As TiNi alloy has excellent superelastic properties and good corrosion resistance ${ }^{2)}$, it is utilized for manufacturing medical devices such as orthodontic wires and medical guidewires. Moreover, in recent years, TiNi alloy is also applied to manufacture stent, which is an implanted medical device in human body and has high risk after being implanted ${ }^{3-5}$. Stents with tube-shaped and netlike metal materials are one of devices for the catheter treatment (percutaneous coronary intervention) and deployed in the vessel stenosis or occlusion to promote enough blood flow by expanding and supporting the vessels. Materials plastically deformed such as stainless steel or CoCr alloys are mainly used as in the coronary artery, while TiNi alloys with superelastic properties are preferably used for the treatment of the artery of lower limb that may transformed by anatomy movement ${ }^{6)}$. This catheter treatment is needed to further invasive procedure such as down-sizing devices. In an effort to maintain the device performance by making diameter small, one of the solutions is to use materials with high strength. Previous studies revealed that TiNi alloy may have high strength and high recovery shape rate by solid-phase sintering of TiNi alloy powder with $\mathrm{TiO}_{2}$ particles ${ }^{7)}$. TiNi alloy powder produced from homogenized a TiNi ingot is easy to obtain homogenous sintered compact and express mechanical/shape-memory properties equal to TiNi alloy castings ${ }^{8)}$, although it has a difficulty in arbitrarily changing composition ratio and limited to design materials. TiNi alloy powder

\footnotetext{
${ }^{* 1}$ This Paper was Originally Published in Japanese in J. Jpn. Soc. Powder Powder Metallurgy 64 (2017) 589-594.

*2Corresponding author, E-mail: Ryouichi_Souba@terumo.co.jp
}

has also economic problems of an increase in processing costs for changing TiNi ingot into powder. In this study, the microstructural and mechanical properties of TiNi alloy with pre-mixed powder of pure $\mathrm{Ti}$ powder and pure $\mathrm{Ni}$ powder is investigated, which are easy to control TiNi composition ratio and inexpensive materials in comparison with TiNi alloy powder. The mechanism of high-strengthened the extruded and heat-treated TiNi alloys by sintering the mixture of TiNi pre-mixed powder with titanium dioxide $\left(\mathrm{TiO}_{2}\right)$ particles is also investigated.

\section{Experimental Procedure}

Pure Ti powder with $99.6 \%$ purity (TC-450: Toho Technical Service Co., Ltd.) and pure Ti powder with $99.6 \%$ purity (SFR-Ni: Nippon Atomized Metal Powders Corporation) were used as a starting material. The results obtained from element analysis of both powder shows in Table 1. Titanium (IV) oxide with $99.5 \%$ purity $\left(\mathrm{TiO}_{2}\right.$, KISHIDA CHEMICAL Co., Ltd.) was used as additive particles. The mixing ratio of $\mathrm{Ti}$ powder to $\mathrm{Ni}$ power was Ti-50.0 at $\% \mathrm{Ni}, \quad \mathrm{Ti}-50.5$ at $\% \mathrm{Ni}, \quad \mathrm{Ti}-51.0$ at $\% \mathrm{Ni}$ and $\mathrm{Ti}-$ 52.0 at $\% \mathrm{Ni}$, respectively. In the mixing procedure, after weighing pure $\mathrm{Ti}$ powder and pure $\mathrm{Ni}$ powder according to prescribed mixing ratio, the powder was sealed in the plastic pot and mixed with desktop ball mill (AV-2: Asahi Rika Factory. Ltd). The mixed powder was sealed with $\mathrm{ZrO}_{2}$ ball (YTZ ball: $\varphi 10 \mathrm{~mm}$, a powder-to-ball weight ratio of 10:1) to mix Ti powder and Ni powder uniformly. The mixed condition was $90 \mathrm{rpm}$ in rotation speed and $10.8 \mathrm{ks}$ in mixed

Table 1 Elemental content analysis of pure Ti and pure Ni powders.

\begin{tabular}{cccccc}
\hline \multirow{2}{*}{ Raw powder } & \multicolumn{5}{c}{ mass\% } \\
\cline { 2 - 6 } & $\mathrm{O}$ & $\mathrm{C}$ & $\mathrm{Fe}$ & $\mathrm{Si}$ & $\mathrm{P}$ \\
\hline Pure Ti powder & 0.22 & 0.01 & 0.03 & 0.01 & - \\
\hline Pure Ni powder & 0.33 & 0.01 & 0.006 & - & 0.028 \\
\hline
\end{tabular}


time, respectively. In manufacturing of TiNi pre-mixed powder added $\mathrm{TiO}_{2}$ particles, after weighing pure Ti, pure $\mathrm{Ni}$ powder and $\mathrm{TiO}_{2}$ particles according to prescribed mixing ratio $\left(0 \mathrm{vol} \% \mathrm{TiO}_{2}, 0.5 \mathrm{vol} \% \mathrm{TiO}_{2}\right.$ and $\left.1.0 \mathrm{vol} \% \mathrm{TiO}_{2}\right)$, the powder was sealed in the plastic pot and mixed with $\mathrm{ZrO}_{2}$ ball $(\varphi 10 \mathrm{~mm}$, ball to powder weight ratio of 10:1) to promote the cancellation of $\mathrm{TiO}_{2}$ particles aggregation. The mixed condition was $90 \mathrm{rpm}$ in rotation speed and $20.6 \mathrm{ks}$ in mixed time, respectively. They were consolidated by spark plasma sintering (SPS) (SPS-1030S: SPS SYNTEX) at $1323 \mathrm{~K}$ for $3.6 \mathrm{ks}$ in vacuum $(\sim 6 \mathrm{~Pa})$ by applying $40 \mathrm{MPa}$ pressure, and were fabricated to a sintered billet with $36 \mathrm{~mm}$ diameter. The dimensions and weight of the sintered billet was measured respectively and the relative density of the sample was calculated. The SPSed billets were pre-heated at $1373 \mathrm{~K}$ for $600 \mathrm{~s}$ in argon (Ar) gas atmosphere with infrared gold image furnace (RHL-P610C: ULVAC, Inc.), and immediately were completely fabricated to powder metallurgy (PM) TiNi alloy rods by hot extrusion (SHP-200-450: Shibayama Kikai Co., Ltd.). Hot extrusion processing conditions was that extrusion ratio was 6 (container with $\varphi 37 \mathrm{~mm}$ inner diameter, die with $\varphi 15 \mathrm{~mm}$ diameter) and that extrusion ram speed was $6 \mathrm{~mm} / \mathrm{s}$. Moreover, the homogenization heat treatment (retention temperature at $1273 \mathrm{~K}, 43.2 \mathrm{ks}$ of retention time, furnace cooling) was applied to the extruded bars for homogenization of organization/composition by vacuum furnace (FT-1200-120: FULL-TECH FURNACE Co., Ltd.). Then, the solution heat treatment (retention temperature at $1273 \mathrm{~K}, 3.6 \mathrm{ks}$ of retention time, $3 \ell / \mathrm{min}$ Ar gas of inlet velocity, water quenching) and the shape memory heat treatment $(773 \mathrm{~K}$ of retention temperature, $3.6 \mathrm{ks}$ of retention time, $3 \ell / \mathrm{min}$ Ar gas of inlet velocity, water quenching) were applied to the rods to precipitate $\mathrm{Ti}_{3} \mathrm{Ni}_{4}$ into the TiNi matrix. The structural analysis and composition analysis to the obtained sample were employed with field emission type scanning electron microscope and energy dispersive X-ray spectroscopy (FESEM-EDS JSM-6500F: JOEL Ltd.), electron probe micro analyzer (EPMA, JXA-8530F: JOEL Ltd.) and X-ray diffraction (XRD-6100: Shimadzu Corporation). Tensile tests were performed under a strain rate of $5 \times 10^{-4} / \mathrm{s}$ at room temperature $(298 \pm 2 \mathrm{~K})$ using a testing machine (Autograph AG-X: Shimadzu Corporation) on tensile bar specimens (a diameter of $3 \mathrm{~mm}$, a gauge length of $15 \mathrm{~mm}$ ), machined from the extruded rods along the extrusion direction. The hysteresis test was also performed under the same conditions and shape recovery rates was measured at $3 \%$ and $8 \%$ strain applied, respectively.

\section{Results and Discussions}

\subsection{Microstructural and mechanical properties of PM TiNi alloy using pre-mixed powder}

The microstructure by SEM of SPSed TiNi using premixed powder (Ti-50.5 at,\% Ni) are shown in Fig. 1. The results exhibited the structure that dispersed compound phase into matrix phase and unreacted pure $\mathrm{Ti}$ and pure $\mathrm{Ni}$ were not detected. There was no void in the dense structure with 99.9\% relative density. Table 2 shows quantitative analysis data of compound phase with EMPA. As 13 at\% oxygen atoms were contained in dispersion phase of a sintered com- pact and the ratio of $\mathrm{Ti}$ to $\mathrm{Ni}$ was $2: 1$, it was concluded that this dispersion phase was $\mathrm{Ti}_{4} \mathrm{Ni}_{2} \mathrm{O}$. As sintering in the sintering process was carried out under vacuum atmosphere, it is conceivable that this $\mathrm{Ti}_{4} \mathrm{Ni}_{2} \mathrm{O}$ was indicated as the oxide that was originated from oxygen atoms contained in the based powder shown in Table 1. Then, SEM observation data at the cross section of as-extruded and homogenization heat treated TiNi alloys are show in Fig. 2 . In $\mathrm{Ti}_{4} \mathrm{Ni}_{2} \mathrm{O}$ phase containing SPSed TiNi alloy, fine spherical particles with $1.2 \mu \mathrm{m}$ mean diameter were dispersed in the entire matrix by performing hot extrusion process. Furthermore, as there are no cracks on the interface between $\mathrm{Ti}_{4} \mathrm{Ni}_{2} \mathrm{O}$ phase and matrix phase in extruded TiNi alloy, it is conceivable that $\mathrm{Ti}_{4} \mathrm{Ni}_{2} \mathrm{O}$ phase can have high interface consistency to the matrix phase. Before and after homogenization heat treatment, significant changes in dispersion regime of $\mathrm{Ti}_{4} \mathrm{Ni}_{2} \mathrm{O}$ particles were not seen. The XRD data of specimens performed solution heat treatment and shape memory heat treatment are shown in Fig. 3 and SEM observation data are shown in Fig. 4. In solution heat treated TiNi alloy, diffraction peaks corresponding to $\mathrm{Ti}_{3} \mathrm{Ni}_{4}$ on the homogenization heat treated TiNi alloy disappeared and needle-like dispersion were not detected from SEM data. This result showed that needle-like $\mathrm{Ti}_{3} \mathrm{Ni}_{4}$ precipitates soluted into TiNi matrix by solution heat treatments. In contrast, in shape memory

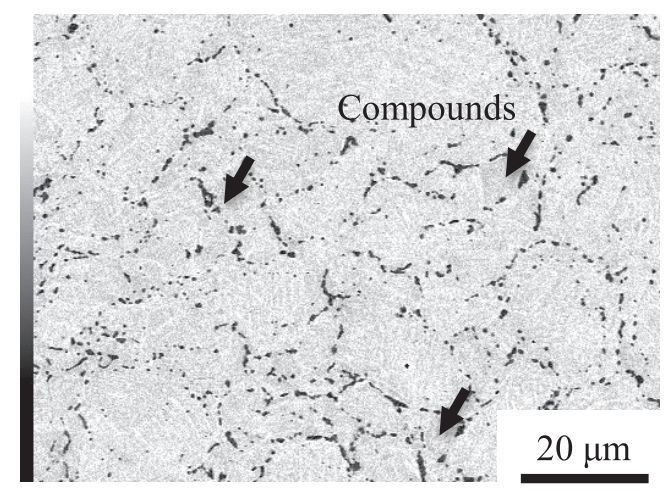

Fig. 1 SEM-EDS observation on cross section of SPSed Ti-50.5 at\%Ni alloy.

Table 2 EPMA point analysis on compounds of SPSed Ti-50.5 at $\% \mathrm{Ni}$ alloy.

\begin{tabular}{cccc}
\hline Element & $\mathrm{Ti}$ & $\mathrm{Ni}$ & $\mathrm{O}$ \\
\hline at\% & 56.5 & 30.5 & 13.0 \\
\hline
\end{tabular}

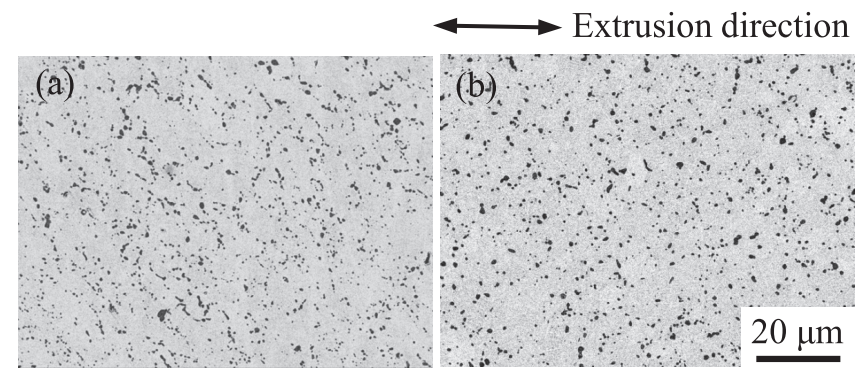

Fig. 2 SEM observation results of as-extruded (a) and homogenization heat treated (b) Ti-50.5 at\% Ni alloys. 


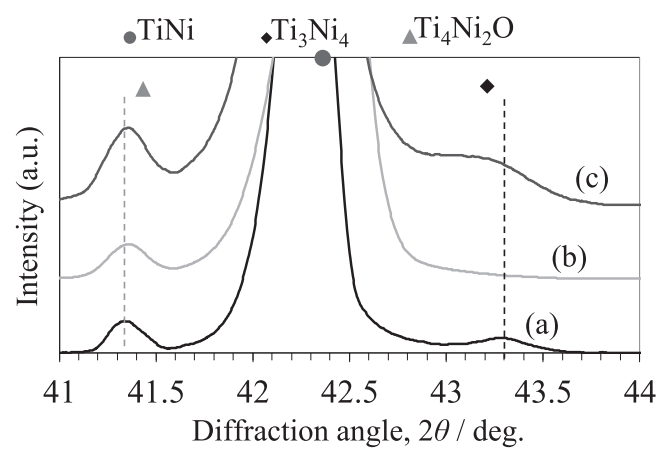

Fig. 3 XRD analysis results of homogenization heat treated (a), solution heat treated (b) and shape memory heat treated (c) Ti-50.5 at\% Ni alloys.

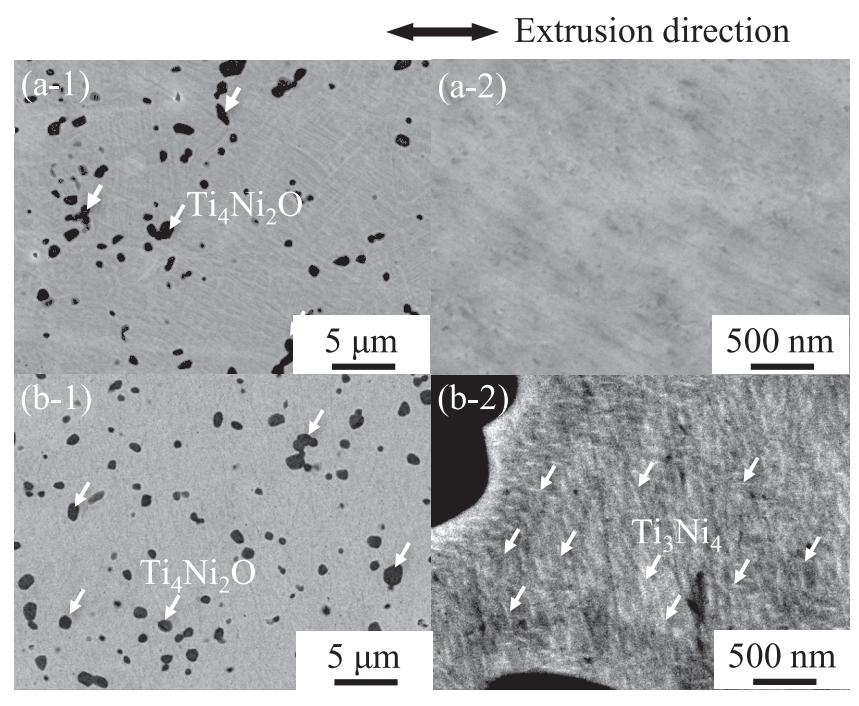

Fig. 4 SEM observation images of solution heat treated (a) and shape memory heat treated (b) Ti-50.5 at $\% \mathrm{Ni}$ alloys.

heat treatment TiNi alloy, diffraction peaks corresponding to $\mathrm{Ti}_{3} \mathrm{Ni}_{4}$ were detected with XRD and the compound precipitated fine particles with below $200 \mathrm{~nm}$ were observed by SEM observation. Figure 5 shows hysteresis test data of shape memory heat treated PM TiNi alloy using pre-mixed powder (Ti-50.5 at\% Ni) and shape memory heat treated PM TiNi alloy using pre-alloyed powder (Ti-51.19 at\% Ni) under the same condition of manufacturing with extrusion and heat treatment. Shape recovery rates $(\mathrm{R})$ were calculated from following formula and calculated data are presented in Table 3.

$$
R=\frac{S_{T}-S_{R}}{S_{T}} \times 100
$$

where, $S_{T}$; applied strain, $S_{R}$; residual strain. Both $S_{T}$ and $S_{R}$ are present in plateau region. In the heat treated PM TiNi alloy using pre-mixed powder, the plateau stress and the end plateau region corresponding in strain were $370 \mathrm{MPa}$ and $4.7 \%$, respectively. By contrast, in the heat treated PM TiNi alloy using pre-alloyed powder which the same heat treatment was performed to, the plateau stress and the end plateau region corresponding in strain were $289 \mathrm{MPa}$ and $6.1 \%$, respectively. Although the strain of the PM TiNi alloy using pre-mixed powder was $2 \%$ lower than one of the PM TiNi alloy using pre-alloyed powder, the plateau stress of the PM

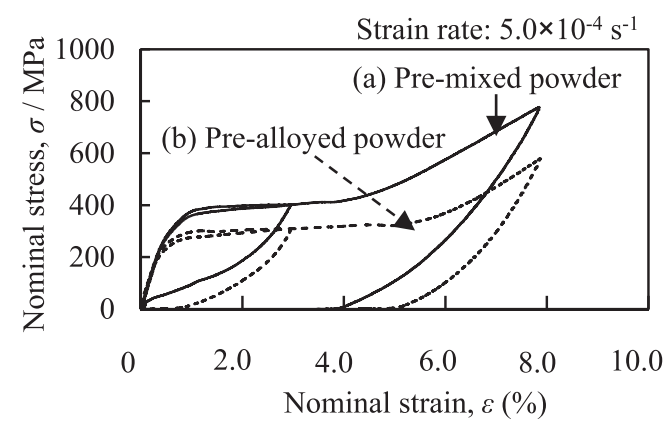

Fig. 5 Stress-strain curves of shape memory heat treated TiNi alloy using Ti-50.5 at $\% \mathrm{Ni}$ pre-mixed powder (a) and $\mathrm{Ti}-51.19$ at $\% \mathrm{Ni}$ pre-alloyed powder (b) in $3 \%$ and $8 \%$ strain applied.

Table 3 Shape recovery rate of shape memory heat treated TiNi alloys.

\begin{tabular}{ccc}
\hline Shape recovery rate, $R(\%)$ & $S_{T}=3 \%$ & $S_{T}=8 \%$ \\
\hline pre-mixed powder & 99.5 & 59.6 \\
\hline pre-alloyed powder & 100 & 46.0 \\
\hline
\end{tabular}

TiNi alloy using pre-mixed powder was $80 \mathrm{MPa}$ higher than one of the PM TiNi alloy using pre-alloyed powder, so the PM TiNi alloy using pre-mixed powder has sufficient mechanical properties to be used as a SMA. When the stress was unloaded at 3\% strain amount in the middle area of plateau region, $99.5 \%$ shape recovery rate was obtained. This result could be explained that the critical stress of slip improved by the matrix phase strengthening action of fine and uniformly precipitated $\mathrm{Ti}_{3} \mathrm{Ni}_{4}$ particles, and by suppressing irreversible deformation by the slip ${ }^{9-11)}$. Moreover, when the PM TiNi alloy using pre-mixed powder was transformed at $8 \%$ strain amount in the work hardening region, approximately $60 \%$ formation of the material recovered owing to unloading the stress. This shape recovery rate was higher compared to the one of the PM TiNi alloy using pre-alloy powder which the same heat treatment was performed to.

\subsection{Microstructures and mechanical properties of PM TiNi alloy using pre-mixed $\mathrm{Ti}-\mathrm{Ni}-\mathrm{TiO}_{2}$ particles}

SEM observation images of TiNi pre-mixed powder (Ti50.5 at $\% \mathrm{Ni}$ ) with $0.5 \mathrm{vol} \%$ and $1.0 \mathrm{vol} \% \mathrm{TiO}_{2}$ particles are shown in Fig. 6. $\mathrm{TiO}_{2}$ particles such as aggregation were not identified, and $\mathrm{TiO}_{2}$ particles were found to attach and disperse on the surface of TiNi pre-mixed powder due to mixing process. SEM observation images of SPSed TiNi alloy using pre-mixed powder are presented in Fig. 7. All the added $\mathrm{TiO}_{2}$ particles were decomposed and disappear, SPSed TiNi alloy using pre-mixed $\mathrm{Ti}-\mathrm{Ni}-\mathrm{TiO}_{2}$ particles became hybrid organization $\mathrm{TiNi}$ phase, $\mathrm{Ti}_{4} \mathrm{Ni}_{2} \mathrm{O}$ phase and needle-like $\mathrm{Ti}_{3} \mathrm{Ni}_{4}$ phase. As unreacted $\mathrm{Ti}$ phase, Ni phase, $\mathrm{Ti}_{2} \mathrm{Ni}$ and $\mathrm{TiNi}_{3}$ phase as intermediate product, SPSed TiNi alloy using pre-mixed powder both with $\mathrm{TiO}_{2}$ particles and without $\mathrm{TiO}_{2}$ particles can react and disperse absolutely. Microstructures by SEM of solution heat treatment and shape memory heat treated extruded TiNi alloy using premixed powder without $\mathrm{TiO}_{2}$ particles (a) and with $\mathrm{TiO}_{2}$ particles (b) and (c) are shown in Fig. 8. Connection and coarsening of dispersed $\mathrm{Ti}_{4} \mathrm{Ni}_{2} \mathrm{O}$ particles were found with 

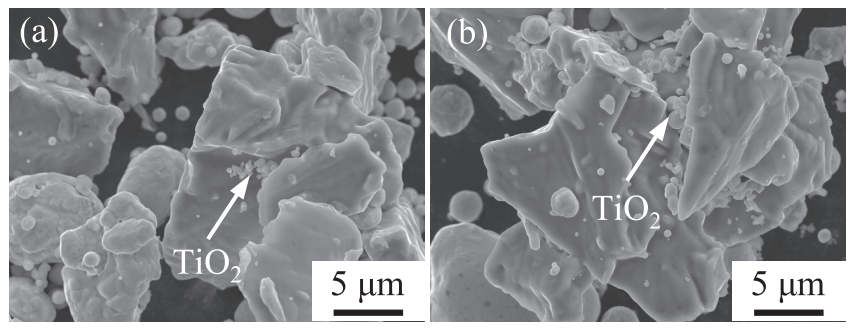

Fig. 6 SEM observation images of Ti-50.5 at\% Ni pre-mixed powders with $0.5 \mathrm{vol} \% \mathrm{TiO}_{2}$ particles (a) and $1.0 \mathrm{vol} \% \mathrm{TiO}_{2}$ particles (b).

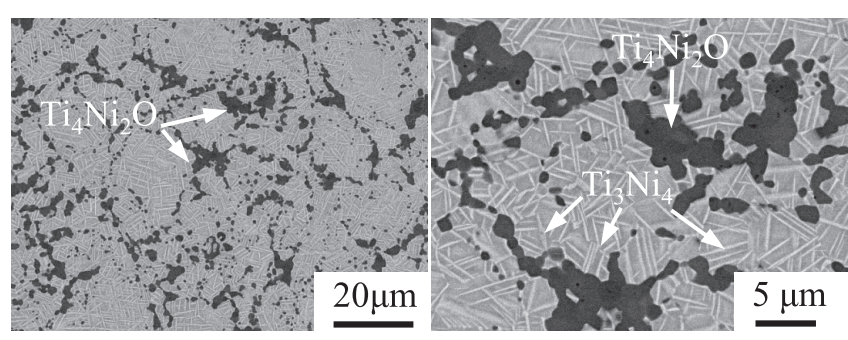

Fig. 7 SEM observation images of SPSed materials using Ti-50.5 at\% Ni pre-mixed powders with $1.0 \mathrm{vol} \% \mathrm{TiO}_{2}$ particles.

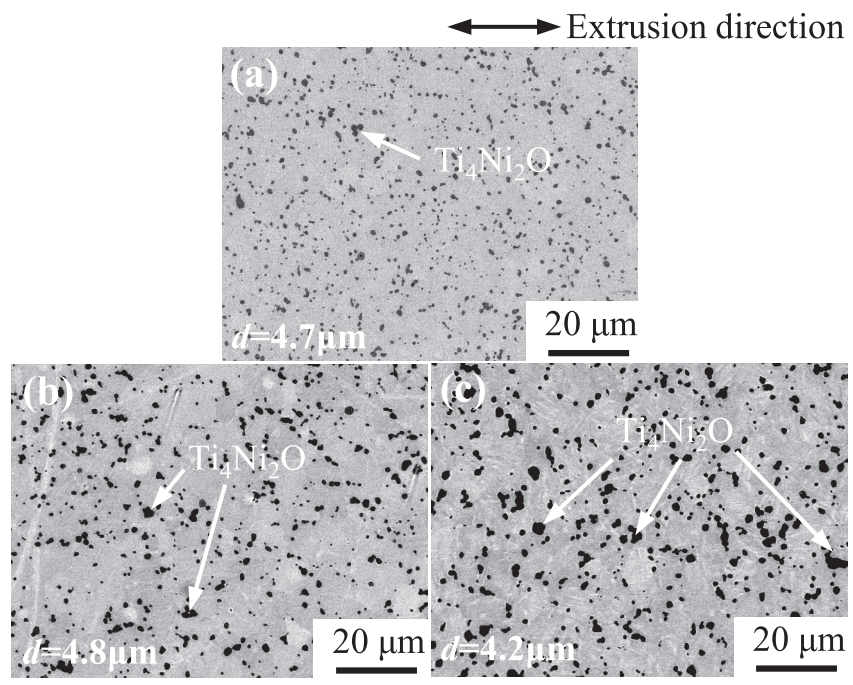

Fig. 8 SEM microstructures of shape memory heat treated Ti-50.5 at $\% \mathrm{Ni}$ alloys without $\mathrm{TiO}_{2}$ particles (a), with $0.5 \mathrm{vol} \% \mathrm{TiO}_{2}$ particles (b) and $1.0 \mathrm{vol} \% \mathrm{TiO}_{2}$ particles (c). increasing $\mathrm{TiO}_{2}$ particles content. It is conceivable that this induced by declining the uniform dispersion when mixing the powder due to the increase in amount of additive $\mathrm{TiO}_{2}$ particles and by producing in the presence of a local uneven distribution. In average grain size of TiNi phase, significant differences were not observed among the addition of the amount of $\mathrm{TiO}_{2}$ particles. Data of tensile test for extruded PM TiNi alloy using pre-mixed powder (mixture ratio of Ti50.5 to $\mathrm{Ti}-51.5$ at $\% \mathrm{Ni}$ ) without $\mathrm{TiO}_{2}$ particles and with $0.5 \mathrm{vol} \%$ and $1.0 \mathrm{vol} \% \mathrm{TiO}_{2}$ particles were listed in Table 4 . The plateau stress of specimens significantly increased with the amount of additive $\mathrm{TiO}_{2}$ particles. Especially for Ti50.5 at $\% \mathrm{Ni}$ alloy with $1.0 \mathrm{vol} \% \mathrm{TiO}_{2}$ particles expressed good mechanical properties, with $630 \mathrm{MPa}$ plateau stress, which is approximately 1.7 times as many as the plateau stress (370 MPa) of Ti-50.5 at\%Ni alloy materials without $\mathrm{TiO}_{2}$ particles. This plateau stress was excellent compared with the plateau stress of PM TiNi alloy (to $600 \mathrm{MPa}$ ) in previous studies ${ }^{12-14)}$. On the other hand, the end plateau region corresponding in strain decreased with the increase in the additions of the amount of $\mathrm{TiO}_{2}$ particles. In shape recovery rates, when unloading $3 \%$ strain in plateau region over 50.5 at $\%$ mixed $\mathrm{Ni}$ amount, $100 \%$ shape recovery rates were shown not the despite the additions of the amount of $\mathrm{TiO}_{2}$ particle. This suggested that a big influence on entire strain were not exerted by dispersing uniformly in the entire substrate without declining ductility of PM TiNi alloy, although $\mathrm{Ti}_{4} \mathrm{Ni}_{2} \mathrm{O}$ particles were brittle compounds. Shape recovery rates showed over $75 \%$ when unloading the stress after the specimen was transformed at $8 \%$ strain amount in the work hardening region. By contrast, in materials of 50.0 at $\%$ mixed Ni amount, when unloading the stress in plateau region, the strain remained over $1 \%$ and the shape recovery rate was $52.3 \%$. It is suggested that residual strain was generated due to occurring slip deformation in plateau region, which caused by decreasing the amount of precipitated $\mathrm{Ti}_{3} \mathrm{Ni}_{4}$ and decreasing critical stress for slip in matrix phase as the mixed $\mathrm{Ni}$ amount equals to the stoichiometric ratio.

\subsection{Strengthening mechanisms of PM TiNi alloy using pre-mixed $\mathrm{Ti}-\mathrm{Ni}$ - $\mathrm{TiO}_{2}$ particles}

Previous section revealed that the increased oxygen atoms by decomposing additive $\mathrm{TiO}_{2}$ particles contributed to generate $\mathrm{Ti}_{4} \mathrm{Ni}_{2} \mathrm{O}$ and that the plateau stress of PM TiNi alloy

Table 4 Modified Ni contents XM-Ni and tensile properties of TiNi alloy composites.

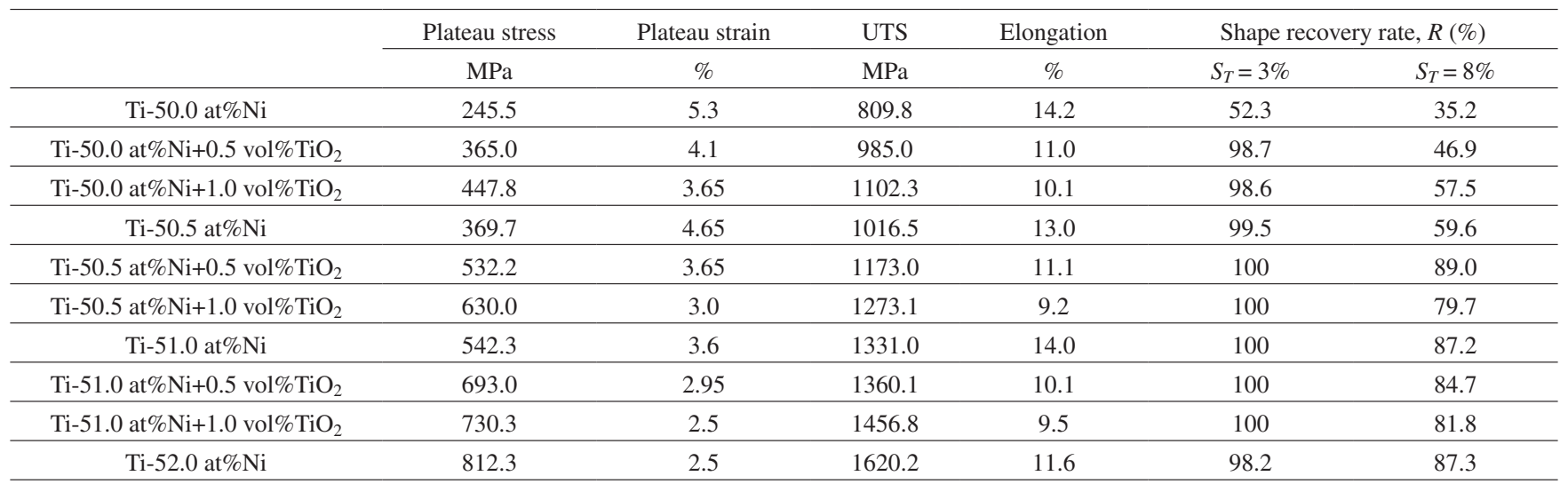


was risen with the increase in the amount of additive $\mathrm{TiO}_{2}$ particles without depending on $\mathrm{Ni}$ content. From these results, when $\mathrm{Ti}_{4} \mathrm{Ni}_{2} \mathrm{O}$ are generated, it is predicted that the changes of mechanical properties are influenced by dispersing $\mathrm{Ti}_{4} \mathrm{Ni}_{2} \mathrm{O}$ particle and by changing in the amount of $\mathrm{Ni}$ solid solution. Although dispersing $\mathrm{Ti}_{4} \mathrm{Ni}_{2} \mathrm{O}$ particle leads to the pinning of the growth of crystal grain, there weren't significant differences among the average grain sizes in TiNi phase depending on the amount of generated $\mathrm{Ti}_{4} \mathrm{Ni}_{2} \mathrm{O}$. It is conceivable that the main strengthening mechanism of TiNi alloy occurs owing to changing in the amount of $\mathrm{Ni}$ solid solution in matrix phase. Therefore, the relation between the plateau stress and the amount of $\mathrm{Ni}$ solid solution accompanying with generating of $\mathrm{Ti}_{4} \mathrm{Ni}_{2} \mathrm{O}$ is considered. A schematic image is presented in Fig. 9, when $\mathrm{Ti}_{4} \mathrm{Ni}_{2} \mathrm{O}$ was generated by the reaction of TiNi including 50 titanium atoms and 50 titanium atoms with one of the $\mathrm{TiO}_{2}$. When one $\mathrm{TiO}_{2}$ molecule is added, one titanium atom increases, while eight titanium atoms and four nickel atoms are consumed by generating $\mathrm{Ti}_{4} \mathrm{Ni}_{2} \mathrm{O}$. Taken all together, the reduction ratio of titanium atom to nickel atom was $7: 4$ and the composition ratio of $\mathrm{TiNi}$ phase relatively changed to Ni-rich side. Therefore, the amount of $\mathrm{Ni}$ solid solution relatively increased by generating $\mathrm{Ti}_{4} \mathrm{Ni}_{2} \mathrm{O}$ described as $X_{M-N i}$ (at $\%$ ) can be calculated from the following equation ${ }^{15}$, when the amount of nickel contained in TiNi pre-mixed $\mathrm{Ti}-\mathrm{Ni}-\mathrm{TiO}_{2}$ particles described as $X_{N i}($ at $\%)$ and the amount of oxygen contained described as $X_{0}$ (at $\left.\%\right)$.

$$
X_{M-N i}=\frac{X_{N i}-2 X_{O}}{100-7 X_{O}} \times 100
$$

Then, the strengthening mechanisms of PM TiNi alloy using pre-mixed powder were considered, when the composition ratio of TiNi phase change to Ni-rich side. The improvement of the plateau stress occurred due to decreasing the martensitic transformation temperature accompanying with the increase in the amount of $\mathrm{Ni}$ solid solution in matrix phase. The relation between stress-induced martensitic transformation $(\sigma)$ and temperature $(T)$ is represented by the following formula from Clausius-Clapeyron equation ${ }^{16)}$.

$$
\frac{d \sigma}{d T}=-\frac{\rho \Delta S}{\varepsilon_{t}}
$$

Herein, $\rho, \Delta S$ and $\varepsilon_{t}$ are a density, a transformation entropy and a transformation strain, respectively. Moreover, when the temperature equals to the martensitic transformation start temperature, the plateau stress is calculated by following formula, as $\sigma$ equals to zero.

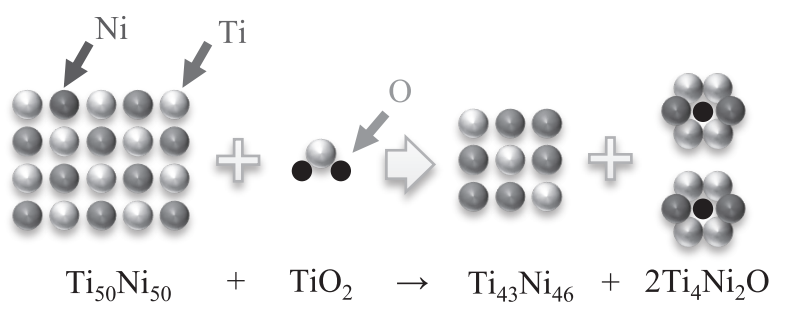

Fig. 9 Schematic image of $\mathrm{Ti}_{4} \mathrm{Ni}_{2} \mathrm{O}$ formation by reaction $\mathrm{TiO}_{2}$ with $\mathrm{TiNi}$.

$$
\sigma_{P}=\frac{\rho \Delta S}{\varepsilon_{t}}\left(M_{S}-T\right)
$$

In this study, when $\rho \Delta S / \varepsilon_{t}$ equals to $-3.03 \mathrm{MPa} / \mathrm{K}^{17,18)}$, an increased amount of the plateau stress per unit the amount of $\mathrm{Ni}$ solid solution is $256 \mathrm{MPa} / \mathrm{at} \% \mathrm{Ni}$ calculated by formula (4). The relation between the amount of $\mathrm{Ni}$ solid solution calculated by formula (2) and the plateau stress listed in Table 4 is shown in Fig. 10. The linear relationship between the plateau stress and the amount of Ni solid solution exists described as the formula (5) and the slope of the formula is $266 \mathrm{MPa} / \mathrm{at} \% \mathrm{Ni}$, despite the additions of the amount of $\mathrm{TiO}_{2}$ particles. This value coincides with the rate of $256 \mathrm{MPa} /$ at $\% \mathrm{Ni}$ increase of the plateau stress calculated by the above theoretical formula (4). The increase in the plateau stress could be explained by decreasing the martensitic transformation temperature associated with rising the amount of Ni solid solution in matrix phase, contributed to generate $\mathrm{Ti}_{4} \mathrm{Ni}_{2} \mathrm{O}$.

$$
\sigma_{p}=265.66 X_{M-N i}-13300
$$

\section{Conclusion}

In this study, powder metallurgy TiNi alloy using premixed powder and powder metallurgy TiNi alloy using premixed powder with $\mathrm{TiO}_{2}$ particles were manufactured in an effort to be examined for high strength and strengthening mechanism of powder metallurgy TiNi alloy. Microstructural analysis, mechanical properties were performed for each TiNi alloy. The result revealed that the composition ratio of TiNi matrix phase could be controled indirectly by adding TiNi pre-mixed powder to $\mathrm{TiO}_{2}$ particles, allowing achieve of high strength/high recovery rate of TiNi alloys. This study provided knowledge as following.

(1) The SPSed TiNi alloys manufactured by pure Ti and $\mathrm{Ni}$ pre-mixed powder exhibited the structure that disperses $\mathrm{Ti}_{4} \mathrm{Ni}_{2} \mathrm{O}$ phase originated from oxygen atoms in the based powder. The powder metallurgy Ti-50.5 at $\% \mathrm{Ni}$ alloy using pre-mixed powder showed $370 \mathrm{MPa}$ plateau stress and $99.5 \%$ shape recovery rate in the end plateau region, whose values were available as shape memory alloys.

(2) The plateau stress of the powder metallurgy Ti50.5 at $\% \mathrm{Ni}$ alloy using pre-mixed powder with $\mathrm{TiO}_{2}$ parti-

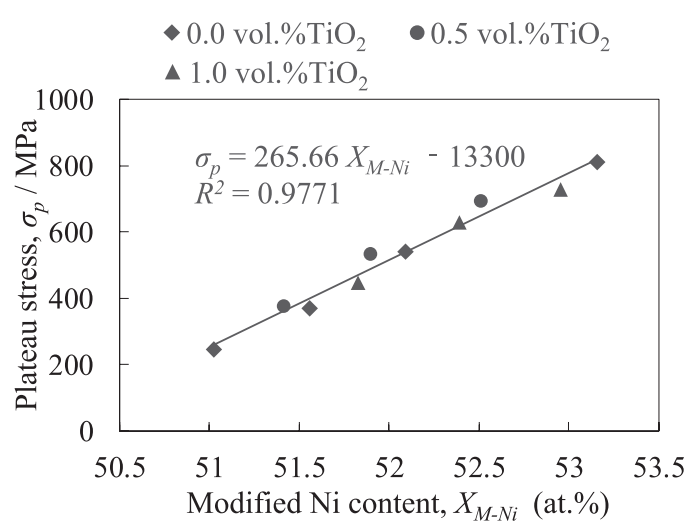

Fig. 10 Dependence of superelastic properties on modified Ni content of TiNi alloys. 
cles significantly increased with increase in the additions of the amount of $\mathrm{TiO}_{2}$ particles. Ti-50.5 at $\% \mathrm{Ni}$ alloy with $1.0 \mathrm{vol} \% \mathrm{TiO}_{2}$ particles expressed good mechanical properties with $630 \mathrm{MPa}$ plateau stress, which is approximately 1.7 times as many as the plateau stress of Ti-50.5 at\% Ni alloy without $\mathrm{TiO}_{2}$ particles.

(3) Strengthening mechanisms of the plateau stress was mainly caused by declining the martensitic transformation temperature due to the increase in the amount of $\mathrm{Ni}$ solid solution. The plateau stress was treated as a linear approximation proportional to the amount of converted $\mathrm{Ni}$ solid solution with the amount of Ni solid solution accompanying with generating $\mathrm{Ti}_{4} \mathrm{Ni}_{2} \mathrm{O}$ phase considered.

\section{Acknowledgments}

A part of this study was financially supported by strategic promotion of innovative research and development program promoted by Japan Science and Technology Agency (JST), Japan.

\section{REFERENCES}

1) S. Miyazaki, T. Sakuma and T. Shibuya: Applications of Shape
Memory Alloys, (CMC Publishing, 2001).

2) D.J. Wever, A.G. Veldhuizen, J. de Vries, H.J. Busscher, D.R.A. Uges and J.R. van Horn: Biomaterials 19 (1998) 761-769.

3) T. Duerig, A. Pelton and D. Stockel: Mater. Sci. Eng. A 273-275 (1999) 149-160.

4) J.K. Allafi, B.A. Ahmadi and M. Zare: Mater. Sci. Eng. C 30 (2010) 1112-1117.

5) P. Filip, J. Lausmaa, J. Musialek and K. Mazanec: Biomaterials 22 (2001) 2131-2138.

6) N.B. Morgan: Mater. Sci. Eng. A 378 (2004) 16-23.

7) T. Yonezawa, T. Yoshimura, J. Umeda, K. Kondoh and R. Souba: Smart Processing Society for Materials 1 (2012) 288-292.

8) T. Koyari, K. Hatano, H. Katoh, S. Miura, M. Tokizane: Proceedings of 1991 Society of Materials Science Japan, 40 (1991) pp. 390-392.

9) K. Otsuka and X. Ren: Prog. Mater. Sci. 50 (2005) 511-678.

10) H. Zhao, C.Q. Liang, J.T. Liu, Y.X. Tong, F. Chen, B. Tian, L. Li and Y.F. Zheng: J. Mater. Eng. Perform. 21 (2012) 2566-2571.

11) M. Nishida, T. Hara, T. Ohba, K. Yamaguchi, K. Tanaka and K. Yamauchi: Mater. Trans. 44 (2003) 2631-2636.

12) K. Funami, Y. Sekiguchi and H. Funakubo: J. Jpn. Inst. Metals 48 (1984) 1113-1119.

13) M. Bram, A.A. Khanlou, A. Heckmann, B. Fuchs, H.P. Buchkremer and D. Stöver: Mater. Sci. Eng. A 337 (2002) 254-263.

14) E.C. Yen and K.S. Hwang: Mater. Sci. Eng. A 528 (2011) 5296-5305.

15) Y. Shugo, S. Hanada and T. Honma: Bulletin of the Research Institute of Mineral Dressing and Metallurgy 41 (1985) 23-34.

16) Y. Liu and H. Yang: Smart Mater. Struct. 16 (2007) S22-S27.

17) K. Otsuka and X. Ren: Prog. Mater. Sci. 50 (2005) 511-678.

18) W. Tang: Metall. Mater. Trans., A 28 (1997) 537-544. 